\title{
Leiomyosarcoma of the vulva: a case report
}

\author{
Masatomo Teramae, Takeshi Fukuda*, Kenji Imai, Makoto Yamauchi, \\ Yasunori Hashiguchi, Tomoyuki Ichimura, Tomoyo Yasui, Toshiyuki Sumi
}

\begin{abstract}
Department of Obstetrics \& Gynecology, Osaka City University Graduate School of Medicine, 1-4-3 Asahimachi, Abeno-ku, Osaka 545-8585, Japan
\end{abstract}

Received: 25 November 2013

Accepted: 15 December 2013

\section{*Correspondence:}

Dr. Takeshi Fukuda,

E-mail: takeshif@med.osaka-cu.ac.jp

(C) 2014 Teramae $\mathrm{M}$ et al. This is an open-access article distributed under the terms of the Creative Commons Attribution Non-Commercial License, which permits unrestricted non-commercial use, distribution, and reproduction in any medium, provided the original work is properly cited.

\begin{abstract}
Sarcomas represent only $1 \%$ to $3 \%$ of vulvar malignancies. Leiomyosarcoma is a rare malignant tumor of the vulva; it can be mistaken for a benign tumor, which can lead to misdiagnosis and incorrect or delayed treatment. We report the case of a 51-year-old woman with leiomyosarcoma of the vulva. The patient presented to her primary gynecologist with a vulvar mass that she had first noticed 20 years prior. The tumor was suspected to be aggressive angiomyxoma, and biopsy of the mass and treatment with gonadotrophin-releasing hormone agonist (GnRHa) therapy were recommended. The patient declined treatment and opted instead for observation; however, the tumor grew rapidly in the following year and the patient was referred to our hospital. She underwent tumor resection, and pathology revealed leiomyosarcoma. The patient declined adjuvant chemo- and radiotherapy but has had no recurrence for 32 months.
\end{abstract}

Keywords: Leiomyosarcoma, Angiomyxoma, Vulva

\section{INTRODUCTION}

The most frequently occurring vulvar primary neoplasm is squamous cell carcinoma. ${ }^{1}$ Sarcoma arising from the vulva is quite rare, representing only $1 \%$ to $3 \%$ of vulvar malignancies. ${ }^{2-4}$ Leiomyosarcoma is the most common histologic type of vulvar sarcoma, ${ }^{5}$ with other types, such as liposarcomas, angiosarcomas, neurofibrosarcomas and epithelioid sarcomas, reported to occur less often. ${ }^{4}$

Leiomyosarcoma of the vulva arises most frequently from the labia majora, followed by, in decreasing order, the Bartholin gland area, clitoris, and labia minora. ${ }^{6}$ The mean age of incidence has been reported to be between 33 and 50 years, with a range of between 15 and 84 years. ${ }^{3,7,8}$ Leiomyosarcoma is a slow-growing tumor that can recur both locally and distantly over a long period. ${ }^{5}$ It is initially painless, and the predominant symptom is often only vulvar discomfort. Because of its rarity, evidence-based treatment algorithms are not available.
We report the case of a patient with leiomyosarcoma of the vulva.

\section{CASE REPORT}

A 51-year-old, gravida 2, para 2 woman presented to her primary gynecologist with a palpable vulvar mass that she had first noticed about 20 years prior. The tumor was suspected to be an aggressive angiomyxoma of the vulva on magnetic resonance imaging (MRI) (Figure 1). She was advised to undergo biopsy of the mass and gonadotrophin-releasing hormone agonist (GnRHa) therapy but declined these treatments and opted instead for observation. Over the following year the mass grew rapidly, and the patient was referred to our hospital for further evaluation and treatment. She had no significant gynecological history. Pelvic examination revealed a painless 8-cm-diameter mass in the right side of the vulva. There were no palpable inguinal lymph nodes. MRI showed a mass with high intensity on T2-weighted images and slightly high intensity on T1-weighted images 
in the right side of the vulva (Figure 2). Computed tomography (CT) of the abdomen and chest was normal. The tumor was resected (Figure 3) and intraoperative frozen section revealed leiomyogenic tumor, but was difficult to determine whether the tumor was benign or malignant. The resected tumor measured $135 \times 110 \times$ $25 \mathrm{~mm}$, weighed $145 \mathrm{~g}$ (Figure 4), and was hard and elastic in consistency. Postoperative microscopic examination of the tumor revealed interlaced bundles of cells with spindles or large blunt-ended nuclei. The mitotic count was 7 per 10 high-power fields. Tumor cells showed immunoreactivity for desmin and ki-67 (Figure 5). Macroscopic examination of the specimen demonstrated leiomyosarcoma of the vulva.

The patient underwent tumor resection without radical vulvectomy. Margins were negative but tumor size was large, and we therefore recommended adjuvant chemotherapy or adjuvant radiotherapy; however, she did not wish to undergo these treatments. She is currently healthy and without evidence of recurrence 32 months after surgery.

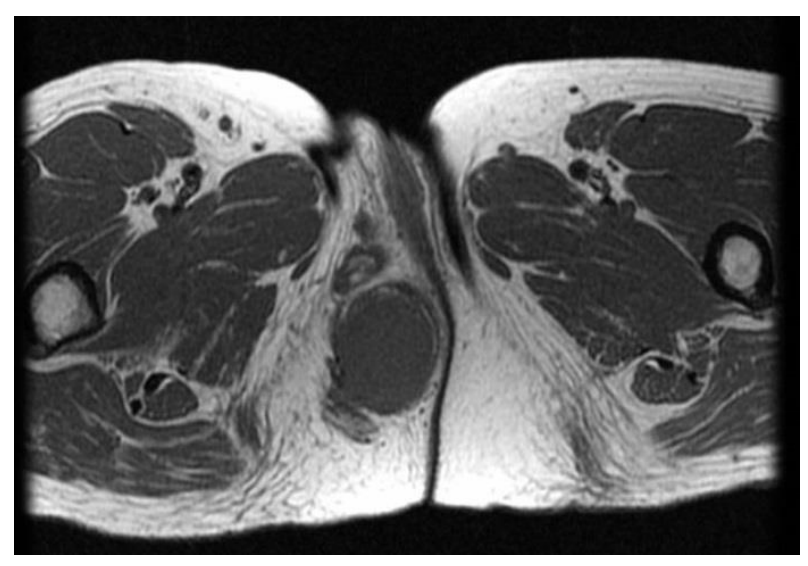

Figure 1A: T1-weighted MRI showing a slightly high intensity mass $(41.8 \times 32.0 \mathrm{~mm})$ in the right vulva.

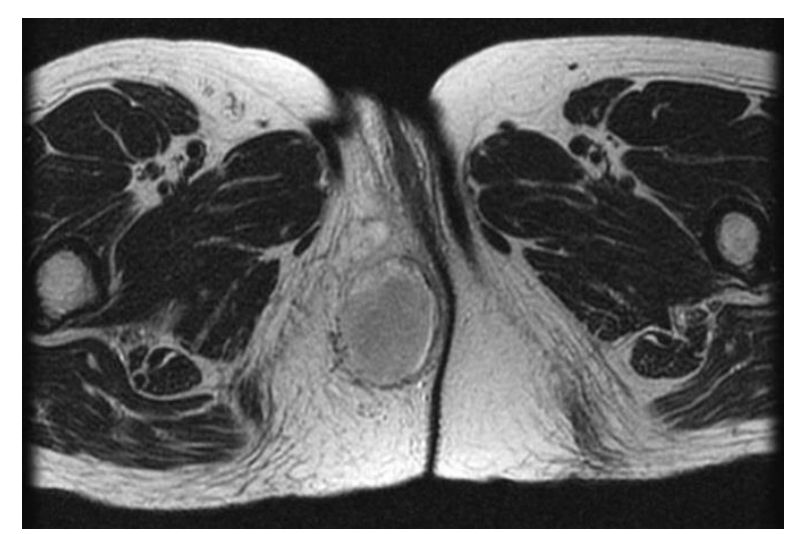

Figure 1B: T2-weighted magnetic resonance image showing a high-intensity mass $(41.8 \times 32.0 \mathrm{~mm})$ in the left vulva.

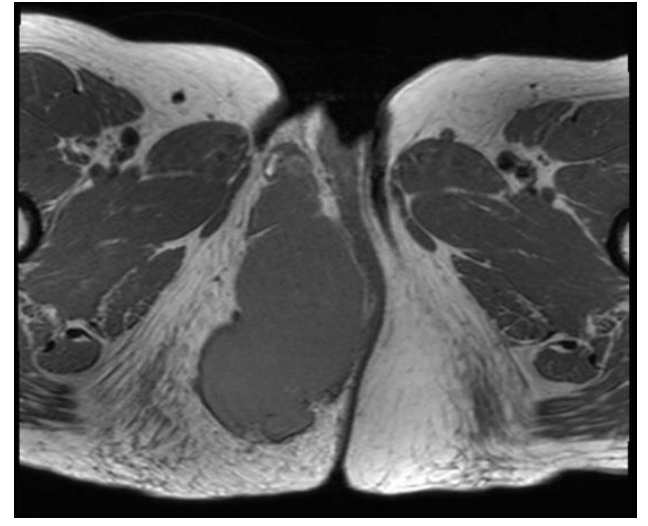

Figure 2A: T1-weighted magnetic resonance image showing a slightly high intensity mass $(106.5 \times$ $45.0 \mathrm{~mm}$ ) in the right vulva.

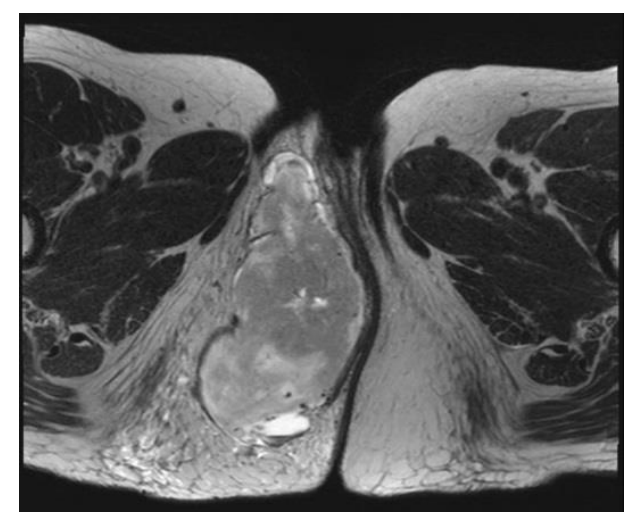

Figure 2B: T2-weighted magnetic resonance image showing a high-intensity mass $(106.5 \times 45.0 \mathrm{~mm})$ in the left vulva.

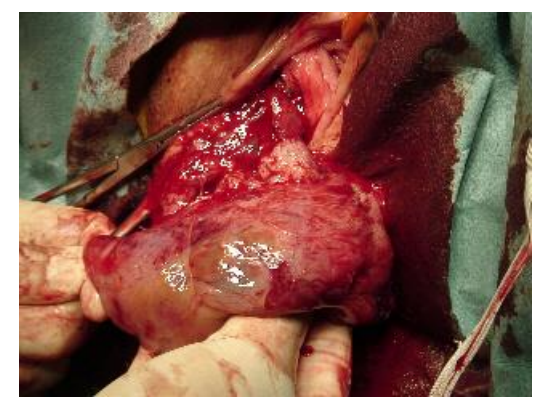

Figure 3: The mass, as seen during the operation.

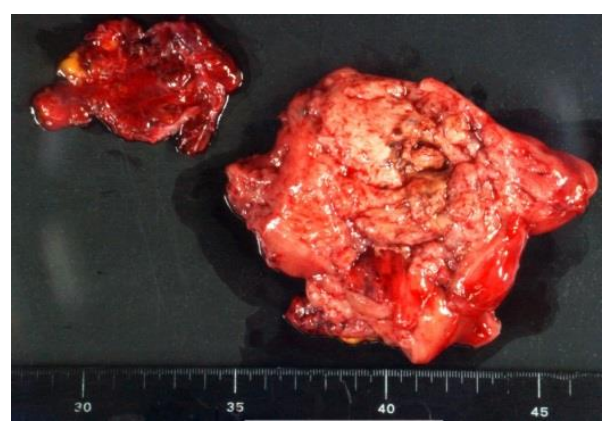

Figure 4: The extracted tumor. 


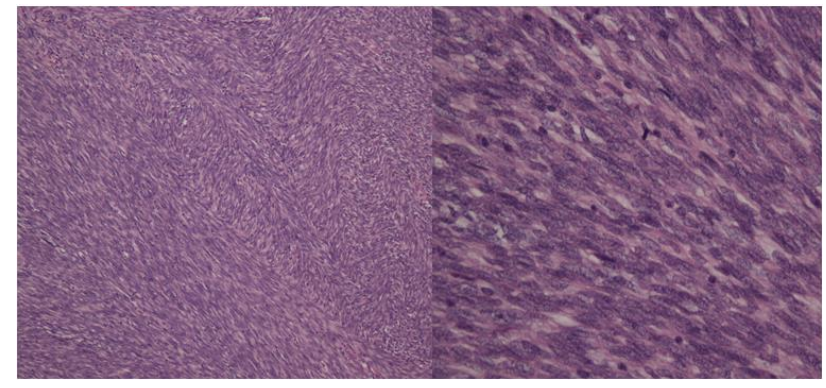

Figure 5A, B: Mesenchymal proliferation of highdensity spindle-shaped smooth muscle cells containing nuclear atypia, pleomorphism, and mitotic figures (A, 100x; B, 400x).

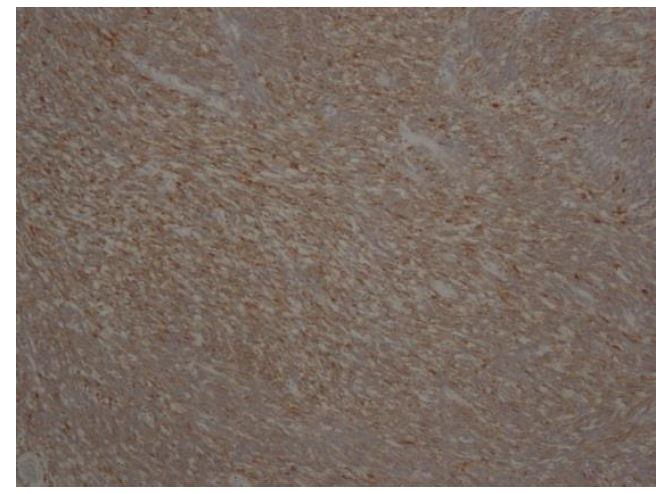

Figure 5C (100x): Tumor cells are diffusely positive for desmin.

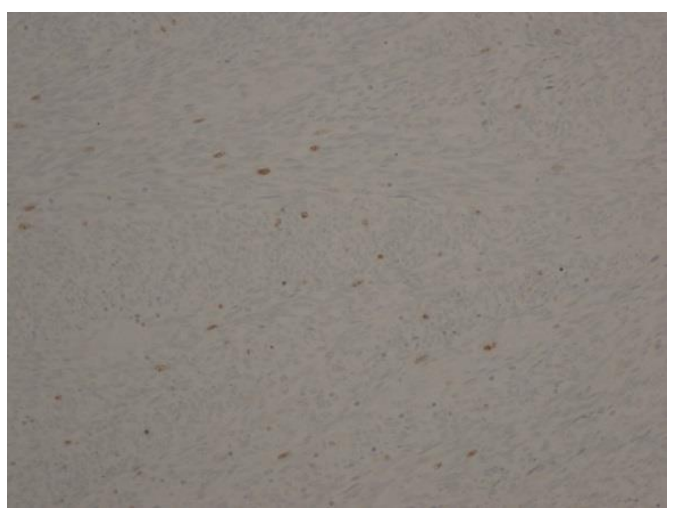

Figure 5D (200x): Tumor cells are diffusely positive for ki-67.

\section{DISCUSSION}

Leiomyosarcoma of the vulva is a rare neoplasm arising from the labia majora, Bartholin gland area, clitoris, or labia minora. The predominant symptoms are often vulvar discomfort and enlarging nodularity. Leiomyosarcomas are thought to derive from smooth muscle cells of the blood vessels, myoepithelial cells of Bartholin's gland, or piloerector muscle cells and can often be mistaken clinically for benign tumors, including leiomyoma, fibroma, lipoma, infectious granuloma, and Bartholin's gland cyst. ${ }^{7,8}$ Misdiagnosis may result in treatment delay and growth of malignant tissue; therefore, correct diagnosis is important. According to Nielsen et al., the most important pathologic findings for a correct diagnosis are tumor diameter of $5 \mathrm{~cm}$ or greater, an infiltrative margin, a mitotic count of 5 or more per 10 high-power fields, and grade 2 or 3 nuclear atypia. If 3 of these 4 criteria are met, leiomyosarcoma is diagnosed; if only 2 are met, atypical leiomyoma; and if 1 or none of the features is present, a diagnosis of leiomyoma is made. $^{8}$

Primary therapy for leiomyosarcoma is surgery, but there is no consensus on surgery type. Several authors have reported that primary treatment is radical vulvectomy with lymph node resection. ${ }^{5}$ Others have reported that wide local excision with clear margins and avoidance of radical vulvectomy in patients with low-grade leiomyosarcoma is a reasonable approach, and that the prognosis of patients who underwent radical vulvectomy was similar to that of patients who underwent wide local excision. ${ }^{3,7}$ Whether adjuvant therapy is necessary remains unclear. For example, in cases of high-grade tumors, margin involvement, or tumor size $>5 \mathrm{~cm}$, radiation is recommended..$^{8-10}$ The important prognostic factors are the size and grade of the tumor. ${ }^{8}$ Our patient underwent only tumor resection, but she is currently healthy and without evidence of recurrence 32 months after surgery.

We have described a rare case of vulvar leiomyosarcoma that presented as a labial tumor. Several types of tumors, including malignant types, can arise from the vulva, such as the rare case of gastrointestinal stromal tumor presenting as a vaginal tumor that we previously reported. ${ }^{11}$ By becoming familiar with the types of tumors that can occur in the vulva, gynecologists can make early diagnosis provide appropriate treatment. This disease is extremely rare, and further study is needed.

\section{Funding: No funding sources \\ Conflict of interest: None declared \\ Ethical approval: Not required}

\section{REFERENCES}

1. Ghurani GB, Penalver MA. An update on vulvar cancer. Am J Obstet Gynecol. 2001;185:294-9.

2. Tjalma WA, Colpaert CG. Myxoid leiomyosarcoma of the vulva. Gynecol. 2005;96:548-51.

3. DiSaia PJ, Rutledge F, Smith JP. Sarcoma of the vulva: report of 12 patients. Obstet Gynecol. 1971;38:180-4.

4. Di Gilio AR, Cormio G, Resta L, Carriero C, Loizzi $\mathrm{V}$, Parisi AM et al. Rapid growth of myxoid leiomyosarcoma of the vulva during pregnancy: a case report. Int J Gynecol Cancer. 2004;14:172-5.

5. Curtin JP, Saigo P, Slucher B, Venkatraman ES, Mychalczak B, Hoskins WJ. Soft-tissue sarcoma of the vagina and vulva: a clinicopathologic study. Obstet Gynecol. 1995;86:269-72. 
6. Androutsopoulos G, Adonakis G, Ravazoula P, Tsapanos V, Kourounis G, Leiomyosarcoma of the vulva: a case report. Eur J Gynecol Oncol. 2005;5:577-8.

7. Losch A, Joura EA, Stani J, Breitenecker G, Lahodny J. Leiomyosarcoma of the vulva: A case report. J Reprod Med. 2001;46:609-12.

8. Nielsen GP, Rosenberg AE, Koerner FC, Young RH, Scully RE. Smooth-muscle tumors of the vulva: A clinicopathological study of 25 cases and review of the literature. Am J Surg Pathol. 1996;20:779-93.

9. Tawfik O, Huntrakoon M, Collins J, Owiety T, Seoud MAF, Weed J. Leiomyosarcoma of the vulva: report of a case. Gynecol Oncol. 1994;54:242-9.
10. Guidozzi F, Sadan O, Koller AB, Marks SR. Combined chemotherapy and irradiation therapy after radical surgery for leiomyosarcoma of the vulva. S A Med J. 1987;71:327-8.

11. Fukuda T, Sumi T, Nakano Y, Morishita M, Nobeyama H, Yoshida H, et al. Extragastrointestinal stromal tumor originating from the vulva. Oncol Lett. $2011 ; 2: 797-9$.

DOI: $10.5455 / 2320-1770$. ijrcog20140345

Cite this article as: Teramae M, Fukuda T, Imai K, Yamauchi M, Hashiguchi Y, Ichimura T, Yasui T, Toshiyuki Sumi Leiomyosarcoma of the vulva: a case report. Int J Reprod Contracept Obstet Gynecol 2014;3:225-8. 